\title{
Is Condensed Better? Comparison of a Condensed Spatial Training Course to a Semester-long Version
}

\section{Ms. Norma L. Veurink, Michigan Technological University}

Norma Veurink is a Senior Lecturer in the Engineering Fundamentals Department at Michigan Technological University where she teaches introductory engineering courses and a spatial visualization course designed for engineering students with poorly developed spatial visualization skills. Ms. Veurink manages several summer programs that introduce middle and high school students to engineering. She is active in the Engineering Design Graphics Division of ASEE.

\section{Dr. Amy J. Hamlin, Michigan Technological University}

AJ Hamlin is a Senior Lecturer in the Department of Engineering Fundamentals at Michigan Technological University, where she teaches first-year engineering courses. Her research interests include spatial visualization, and educational methods. She is an active member in the Engineering Design Graphics Division of ASEE and is currently serving as the Editor of the Engineering Design Graphics Journal. 


\title{
Is Condensed Better? Comparison of a Condensed Spatial Training Course to a Semester-long Version
}

\begin{abstract}
This research paper presents a study on the impact of offering a remedial spatial training course over a condensed time frame. In this paper spatial skill development will be compared for students taking a traditional semester-long spatial training course with students taking the course over the first half of a semester. Grades in the training course and spatial test scores will be compared to determine student spatial development as a result of the course. Student attitudes about the timing of the course were surveyed at the end of the course to determine if they preferred a full- or half-semester offering of the course. Determining if a condensed version of a spatial training course is equivalent or better than a longer version may give institutions offering remedial spatial training courses more options for offering the training to their students.
\end{abstract}

\section{Background}

Many universities are implementing spatial visualization training courses to assist students with poorly developed spatial visualization skills based on research that has shown that students with initially weak spatial visualization skills that receive spatial training have higher retention rates and higher grades in STEM courses commonly taken during their first-year (such as Calculus I) than students with comparable visualization skills who do not take the spatial training. Through the National Science Foundation funded ENGAGE (Engaging Students in Engineering) program, over 41 post-secondary schools have implemented spatial visualization testing and training programs $^{1}$. ENGAGE recommends the use of the "Developing Spatial Thinking” workbook ${ }^{2}$ and software created by Dr. Sheryl Sorby in spatial training programs. The workbook and software contain 10 modules, and many of the schools that offer a spatial training targeted for students with poorly developed spatial skills, offer the training in once-weekly sessions that follow several or all of the modules in the workbook, while a smaller number of schools offer the training in a more condensed format through summer bridge programs or twice weekly sessions ${ }^{1,3-5}$. No studies have been published to date that examine whether the effectiveness of the training is related to the time frame over which the training is conducted.

A number of universities and organizations have offered condensed versions of a variety of courses. Some have created accelerated courses and programs to accommodate the needs of non-traditional and part-time students ${ }^{6}$. Others universities offer intensive courses during summer or interim terms - a short term between the regular semesters (January or May terms). A review of intensive and traditional courses for a variety of disciplines by Scott and Conrad ${ }^{7}$ found that when evaluating short-term measures (pre- and post-tests, exam scores, and course grades) and long term outcomes (post-tests administered several months later), the intensive courses are equivalent and sometimes superior to the traditional course formats.

\section{Description of the Study}

Spatial visualization skills of incoming engineering freshmen at Michigan Technological University have been assessed through the Purdue Spatial Visualization Test: Rotations 
(PSVT:R) developed by Guay ${ }^{8}$ since 1993 . Students scoring $60 \%$ or below on the PSVT:R have been encouraged or required to take a spatial visualization training course since that time. From 1993 through 1999, Michigan Tech operated on the quarter system and the spatial training course was offered as a 3-credit, 10 week course that met for two 1 - hour lectures and two hours of lab each week ${ }^{9}$. The course utilized hands on construction activities, paper and pencil sketching activities, and solid modeling activities that corresponded to the course topics. In the fall of 2000, Michigan Tech converted to the semester system and from 2000 to 2002, the spatial training course was offered as a 1-credit, 15 week course that met once weekly for two hours (110 minutes) of lab. In this 1-credit course, the instructor introduced the topic for the day in a 10 to 20 minute lecture after which students worked through software specifically developed for the course and completed assigned pages in the Introduction to 3D Spatial Visualization workbook $^{10}$. A 2005 study by Sorby ${ }^{11}$ concluded the 1-credit semester course was as effective in improving spatial skills as the 3-credit quarter system course.

Since 2005, the spatial visualization course has been offered as a 14-week course that meets for 80 minutes over a 14-week semester. The 80 minute session is conducted in much the same manner as the 2000 - 2002 version of the course, where students are introduced to the topic of the day in a 15 to 20 minute lecture and in-class exercises, work through software module exercises, and then complete workbook pages that are assigned as homework. For most topics, students are able to complete the homework during the 80 minute class session. The course covers all ten modules in the "Developing Spatial Thinking" workbook by Sorby", and includes two quiz days, pre-testing on the first day of class, and post-testing on the last day of class. One class day is also spent on sketching exercises similar to those developed by Diarmaid Lane and Niall Seery ${ }^{12}$. A final comprehensive exam is given during the final exam period.

About half of the students taking the spatial training course are concurrently taking an introductory engineering course which includes graphics instruction. The graphics instruction in the engineering course is purposely placed at the end of the semester to allow students taking the spatial training course to improve their spatial visualization skills before that topic is covered in the engineering course. However, because both the engineering and the spatial training courses span the entire semester, the graphics instruction occurs in the engineering course before the students have completed the spatial training course. This results in some graphics topics being taught in the engineering course before the topic is introduced in a more thorough manner in the spatial training course. Also, toward the end of the semester, some students in the spatial training course appear to be pre-occupied with their other courses and begin to work on homework for other courses during the spatial training class or leave the spatial training class immediately after the lecture portion instead of staying and completing the workbook pages assigned as homework.

In order to address these issues and in preparation for potential first year engineering curriculum changes, in Fall 2014 and Fall 2015 two of four sections of the spatial training course were offered twice a week for the first half the semester to determine if offering a condensed spatial training results in 1) equivalent or better improvement in spatial skills and 2) improved student engagement over the once-weekly full semester course offering. Scores on common spatial tests, spatial training final exam scores, and course grades were compared for the two groups. 
Additionally, a survey was administered to students in the two groups to determine student preferences for either the traditional semester-long course or the half-semester course.

In fall 2014, two instructors taught the four sections of the spatial training course. Each instructor taught one full-semester and one half-semester section of the course. In fall 2015, one instructor taught all four sections of the course included in the study. In this manner, instructor effects would not bias the results.

\section{Study Participants}

Students in the study were freshmen engineering students at Michigan Tech. The majors represented in the study include mechanical, electrical, chemical, environmental, civil, materials science, computer, biomedical, and engineering undecided students. All students in the study scored $60 \%$ or below on the PSVT:R and were required to take the spatial training course. Students were randomly placed in the half-semester or full-semester course by the registrar. Over the two semesters, 146 students took the half-semester spatial training course while 152 students took the full-semester version of the course. The students in the half-semester course were told they were in a trial version of the course as it was typically offered over the entire semester, while the students in the full-semester version were not told anything regarding the two different offerings of the course.

Students in the experimental and control groups seemed to be equally matched as far as pre-test PSVT:R and math ACT scores as shown in Figure 1 below. Students in the study on average scored about 15 out of 30 on the PSVT:R administered during orientation. There was no statistical difference in the PSVT:R scores of the students in the half-semester (experimental) and the full-semester (control) groups. Math ACT scores of the two groups were also compared, and again, there was no statistical difference between the Math ACT scores of the two groups.

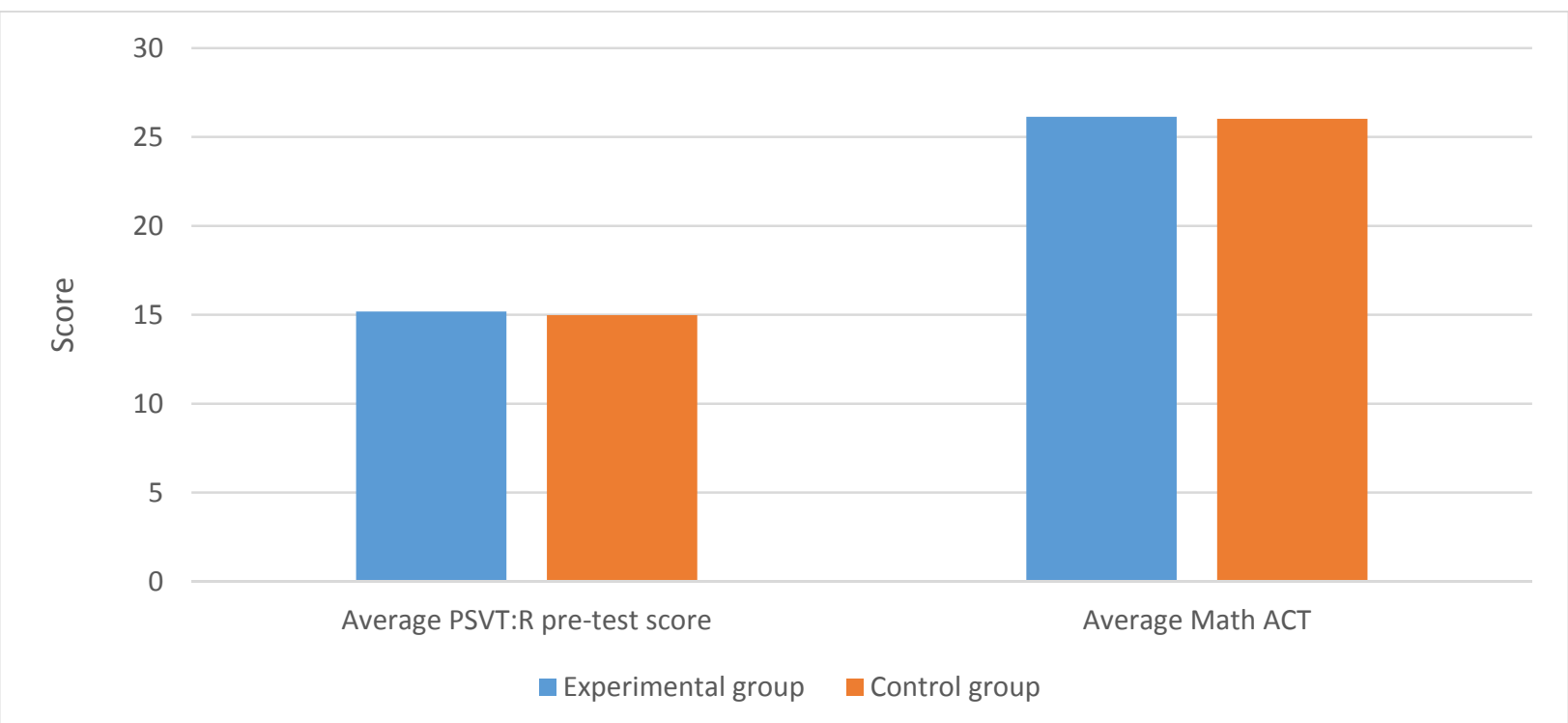

Figure 1: Comparison of PSVT:R pre-test and Math ACT scores of the experimental and control groups 


\section{Discussion of Results}

In addition to the PSVT:R test administered during orientation in order to identify those who would benefit from spatial training, two other standard spatial visualization tests are administered to the students in the first day of the spatial training course: The Mental Rotations Test (MRT-A), and a 10-question version of the Mental Cutting Test (CEEB). As with the PSVT:R and Math ACT scores, there were no statistically significant differences on the MRT-A and MCT pre-test scores between the two groups. These tests and the PSVT:R are administered again on the last class day in order to measure spatial visualization gains for the students. Posttest scores on these three tests were compared for the experimental and control groups, and as for the pre-test scores, no statistically significant difference between scores of the two groups was found. However, when comparing gains from pre- to post-test scores, the experimental group showed slightly larger gains. The gains from pre- to post-test scores are compared in Figure 2 below.

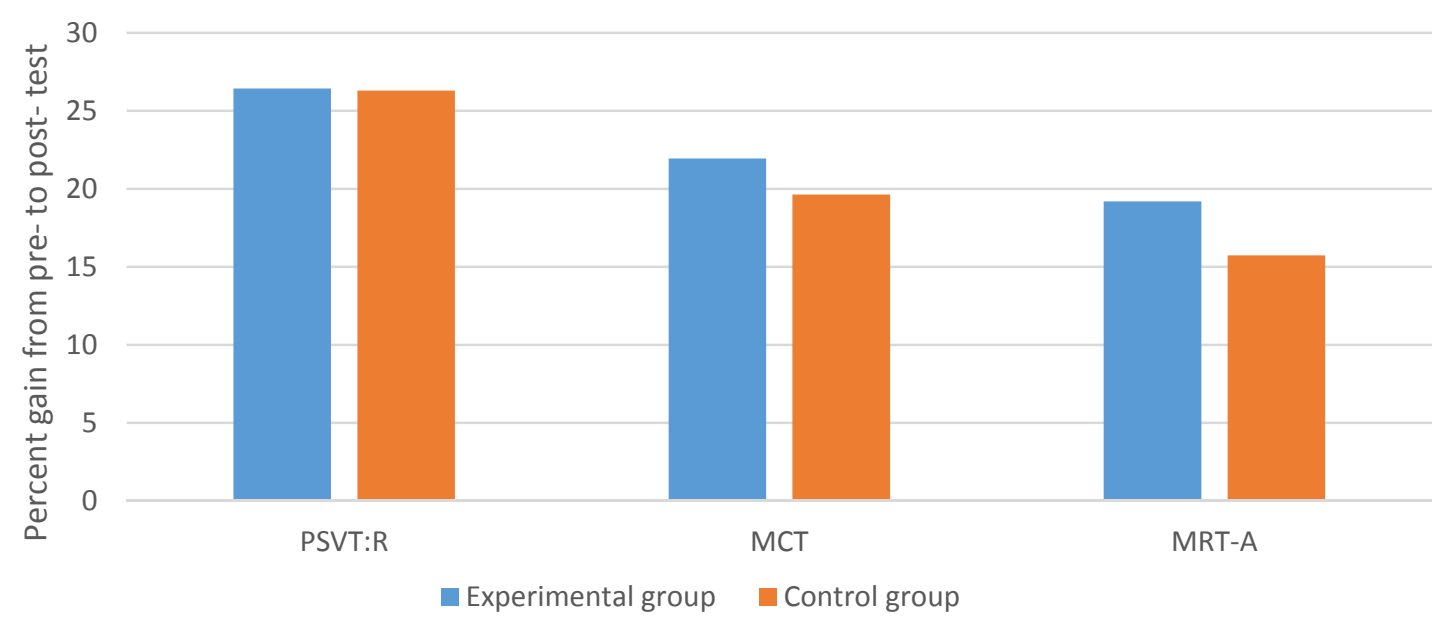

Figure 2: Comparison in gains from pre-test to post-test scores on standard spatial tests

A final exam is given in the course during final exam week for the full semester course, while the final exam was given on the evening of the last day of class for the half-semester course. The final exam is comprehensive, covering all but two of the ten workbook modules, and students in both the experimental and control groups were given an identical final exam. As with the spatial test scores, no statistically significant differences in the final exam scores of the two groups was found. However, when comparing overall grades in the course (on a 4-point scale), the experimental group had marginally statistically higher overall course grades than the control group $(p=0.04)$. The overall course grades are shown in Figure 3 below. Course components that contribute to the overall course grade include homework, attendance, two quizzes, the posttest scores, and the final exam grades. One reason the experimental group may have had higher overall course grades could be because only two students in the study failed the course, and both students were in the control group. 


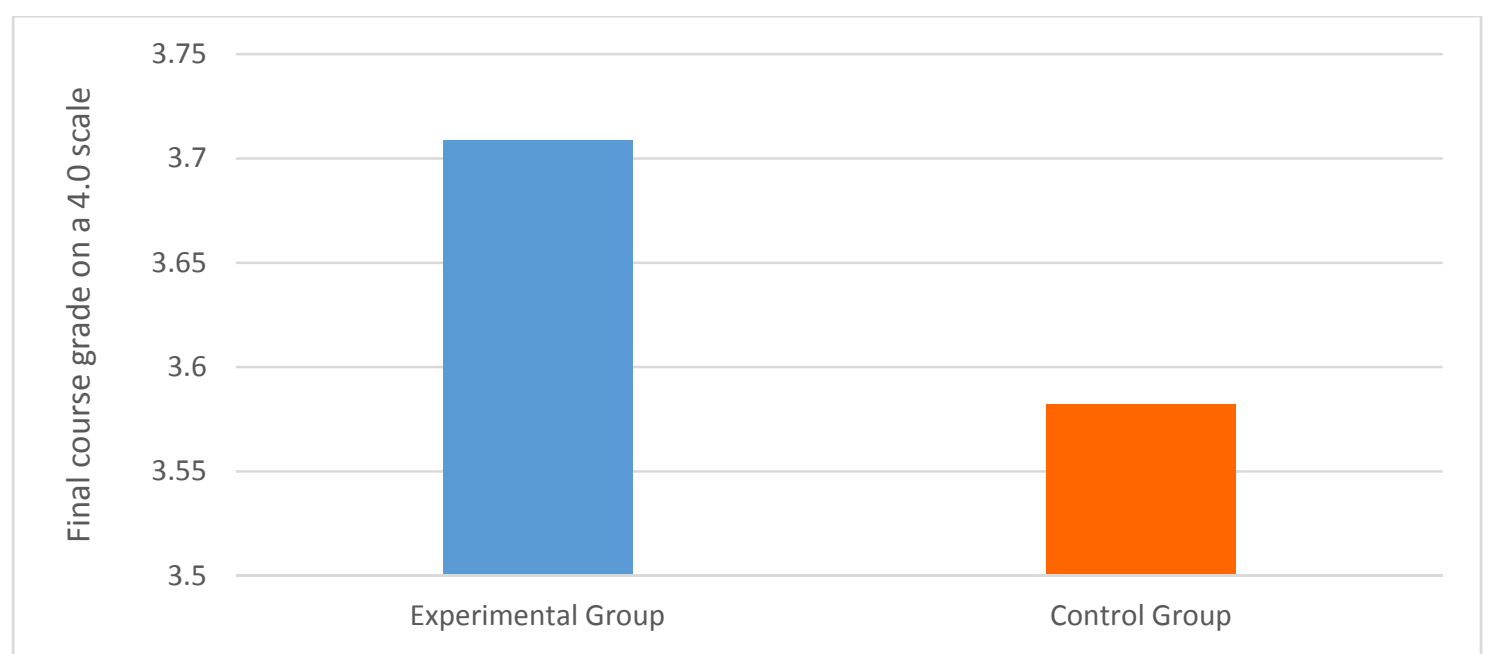

Figure 3: Comparison of final grades in spatial training course

To determine if the students had a preference for the length of training they received, all students were given a survey at the end of their training. The students in the full-semester version of the course (control group) were asked to rate their level of agreement with the following two statements on a five-point Likert scale (Strongly Disagree to Strongly Agree):

1. I liked that the course met once a week and lasted the entire semester.

2. I would have preferred meeting twice a week and completing the course in half a semester.

These students were given a paper version of the survey during their last class period during $14^{\text {th }}$ week.

The survey response rate for the full-semester students was 94\%, with 143 of the 152 students completing the survey. Control group student responses, shown in Figure 4, indicate general satisfaction with the full-semester training as nearly half the students (47\% of respondents) agreed or strongly agreed that they liked that the training lasted the full-semester with another $24 \%$ that were neutral. However, $25 \%$ of the students did not like having the training over the full-semester and as shown in Figure 5, nearly 50\% of the students in the full-semester course reported that they would have preferred meeting twice a week for only half the semester. 


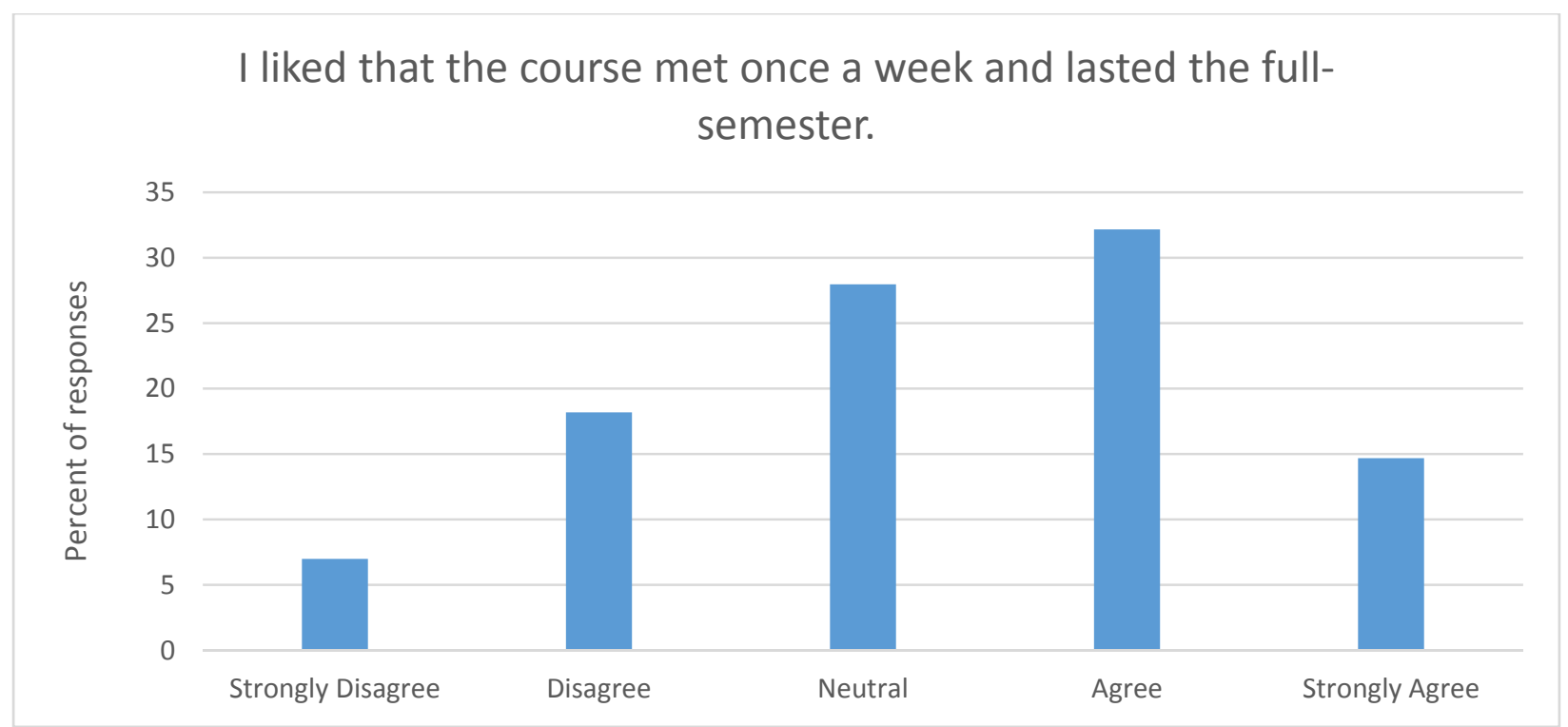

Figure 4: Control group responses to the statement, I liked that the course met once a week and lasted the full-semester.

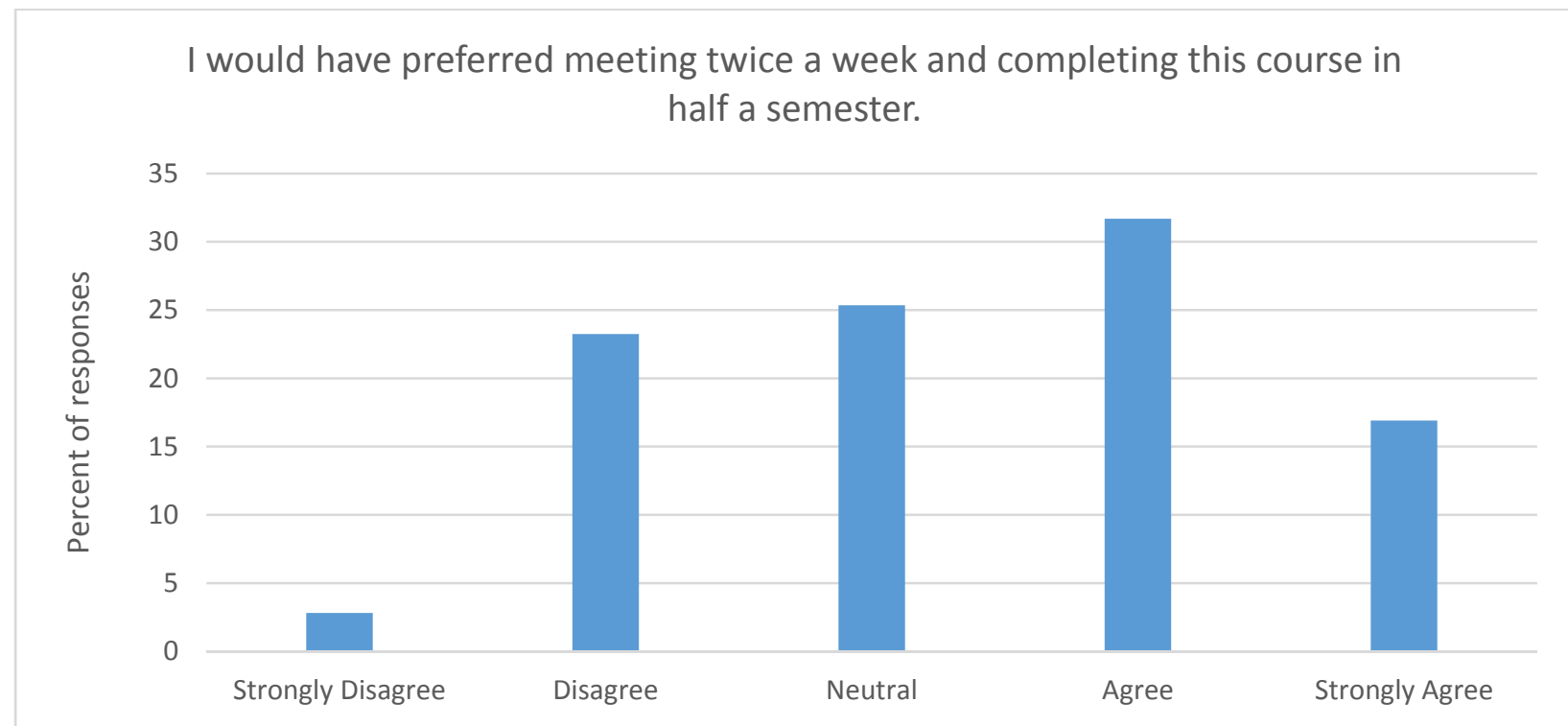

Figure 5: Control group responses to the statement, I would have preferred meeting twice a week and completing this course in half a semester

Students in the half-semester version of the course were given a survey similar to the students in the full-semester version. These students were asked to rate their level of agreement to the following statements (Strongly Disagree to Strongly Agree):

1. I liked that the course met twice a week and lasted half the semester.

2. I would have preferred meeting once a week over the full semester.

Three of the four half-semester sections of the course were given a paper survey to complete during their last class period of their training in week 7, while one of the half-semester sections 
was given the same survey electronically using doodle poll at the end of the semester. The electronic survey was sent out eight weeks after the half-semester training was completed at the same time the full-semester students were completing their surveys. While the response rate from the half-semester students that received the electronic survey (17 of the 42 students, 40\%) was lower than those receiving the paper survey (98 of 104 students, 94\%), their responses were similar to those that received the paper survey, as shown in Figures 6 and 7. It is clear from these figures, that the students in the half-semester version of the course liked it. More than $90 \%$ of the students agreed (65\% of the students strongly agreed) that they liked meeting twice a week and $90 \%$ of the students indicated that they would not have preferred meeting once a week.

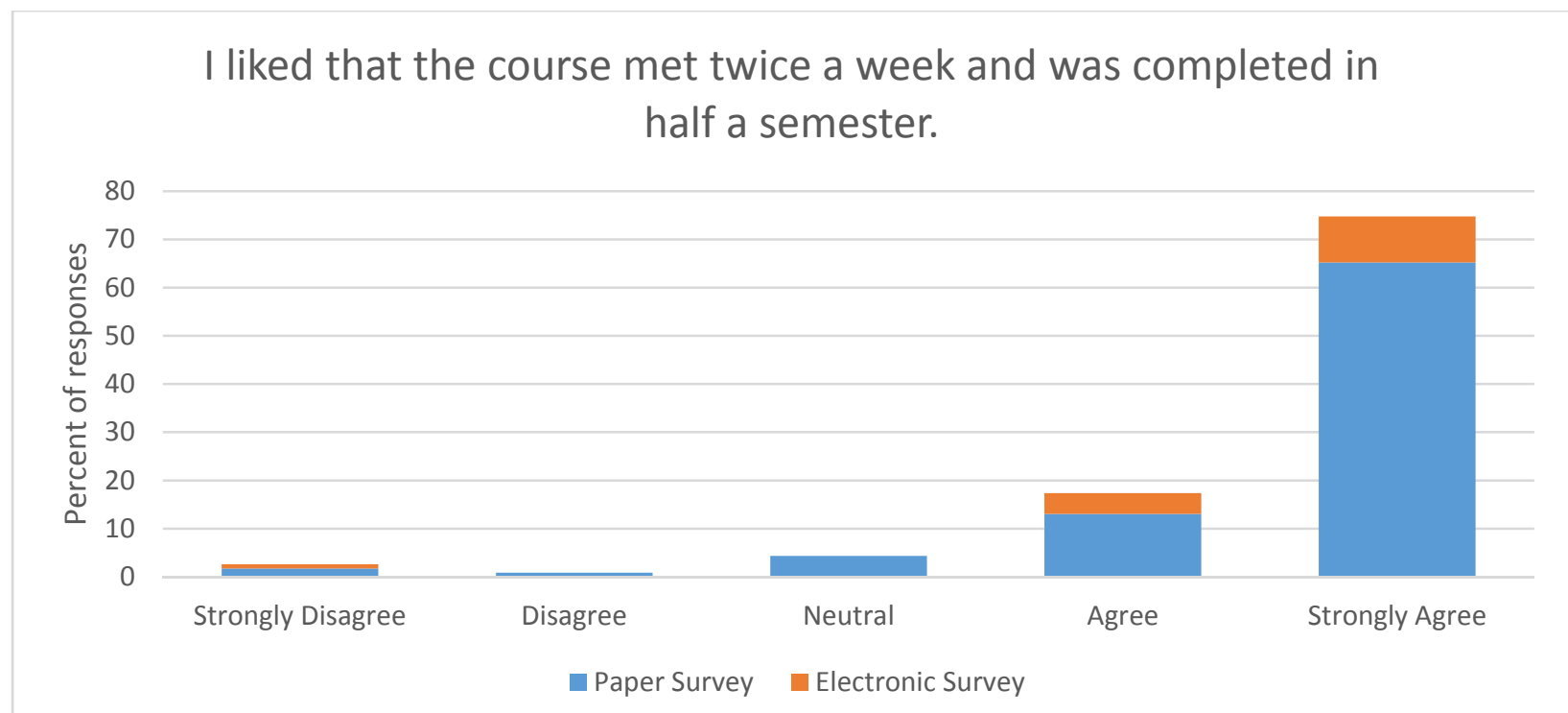

Figure 6: Experimental group responses to the statement, I liked that the course met twice a week and lasted half the semester.

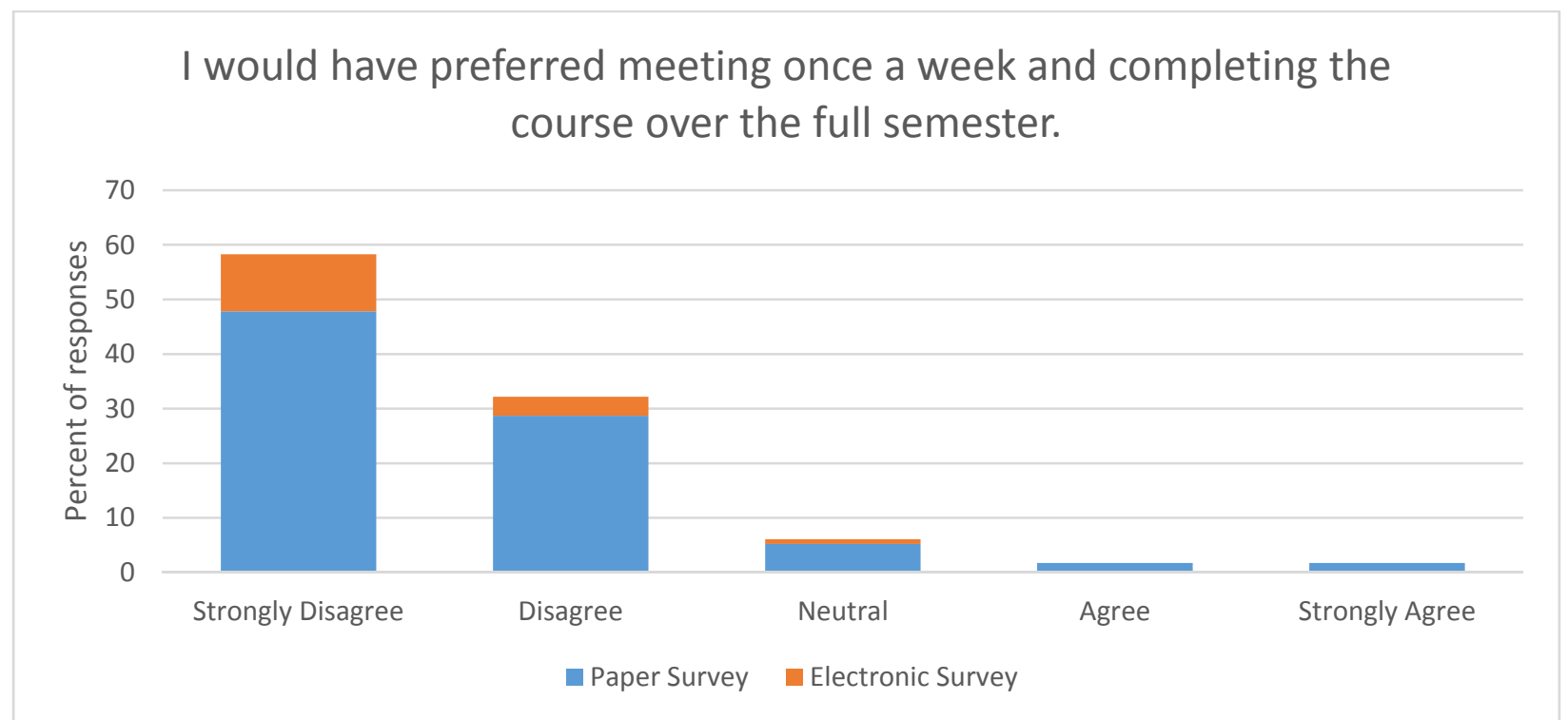

Figure 7: Experimental group responses to the statement, I would have preferred meeting once a week over the full semester. 


\section{Conclusion}

In this study a spatial training course was offered in the traditional format, once a week for 14 weeks, and in a condensed version, twice a week for the first 7 weeks of the semester. A comparison of incoming spatial skills as measured using the pre-test results from the PSVT:R, MRT, and MCT indicates that there was not a statistically significant difference between incoming spatial skills for the two groups. Post spatial test results indicate that the condensed version of the course results in equivalent or slightly better gains than the full-semester version of the course. Results from student surveys indicate the students prefer the condensed training.

Future work includes post-testing the students in the study at the end of their first year in order to determine if spatial skills are retained at the same rate for the two groups.

\section{References}

1. $\quad$ Engage Engineering. Spatial Visualization Skills (SVS): Learn More [Online]. Available: http://www.engageengineering.org/spatial/whyitworks/learnmore\#4. [Accessed 1- Feb- 2016].

2. S. Sorby and A.F. Wysocki, Developing Spatial Thinking. Clifton Park, NY: Delmar Cengage Learning, 2012.

3. S.P. Walton, M. Urban-Lurain, A. Idema, T.J. Hinds, and D. Briedis, "Spatial Visualization Skills Intervention for First Year Engineering Students: Everyone’s a Winner!” in $122^{\text {nd }}$ American Society of Engineering Education Annual Conference \& Exposition, Seattle, WA, 2015.

4. N.L. Veurink, et al. "Enhancing Visualization Skills-Improving Options aNd Success (EnViSIONS) of Engineering and Technology Students”, Engineering Design Graphics Journal, vol. 73, no. 2, Spring 2009.

5. K.S. Harris, L.V. Harris, and M.A. Sadowski, "Measuring Spatial Visualization in a High School Bridge Program," in 64th Midyear Meeting of the Engineering Design Graphics Division of ASEE, Erie, PA, 2009.

6. R.J. Wlodkowski, “Accelerated Learning in Colleges and Univeristies,” New Directions for Adult and Continuing Education, no. 97, pp. 5-15, Spring 2003.

7. P.A. Scott and C.F. Conrad, "A Critique of Intensive Courses and an Agenda for Research," Higher Education: Handbook of Theory and Research, vol. 8, pp. 411-459, 1991.

8. R.B. Guay, "Purdue spatial visualization test: Rotations," Purdue Research Foundation, West Lafayette, IN, 1977.

9. S.A. Sorby and B.J. Baartmans, "The Development and Assessment of a Course for Enhancing the 3-D Spatial Visualization Skills of First Year Engineering Students,” Journal of Engineering Education, vol. 89, no. 3, pp. 301-307, 2000.

10. S. Sorby and A.F. Wysocki, Introduction to 3D Spatial Visualization an active approach. Clifton Park, NY: Delmar Learning, 2003.

11. S. Sorby, "Impact of Changes in Course Methodologies on Improving Spatial Skills," Journal for Geometry and Graphics, vol. 9, no. 1, pp. 99 - 105, 2005.

12. D. Lane and N. Seery, "Freehand Sketching as a Catalyst for Developing Concept Driven Competencies," $117^{\text {th }}$ American Society of Engineering Education Annual Conference \& Exposition, Louisville, KY, 2010. 